\title{
Nuclear p27 Expression Confers a Favorable Outcome for Nasopharyngeal Carcinoma Patients
}

\author{
Zhen Liu, ${ }^{1,2}$ Yufei Long, ${ }^{2,3}$ Yajie Zhang, ${ }^{1,2}$ Wei Huang, ${ }^{2}$ Xiaobin Long, ${ }^{2,4}$ Huiling Yang, \\ Jie Long, ${ }^{1}$ Chao Cheng, ${ }^{2,4}$ and Weiyi Fang ${ }^{2}$ \\ ${ }^{1}$ Department of Pathology, Basic School of Guangzhou Medical University, Guangzhou 510182, China \\ ${ }^{2}$ Cancer Research Institute, Southern Medical University, Guangzhou 510515, China \\ ${ }^{3}$ Clinical Medicine 2010, Southern Medical University, Guangzhou 510515, China \\ ${ }^{4}$ Pediatric Center of Zhujiang Hospital, Southern Medical University, Guangzhou 510282, China \\ ${ }^{5}$ School of Pharmacy, Guangdong Medical College, Dongguan 523808, China
}

Correspondence should be addressed to Chao Cheng; nurswan@126.com and Weiyi Fang; fangweiyi1975@163.com

Received 25 June 2013; Revised 23 September 2013; Accepted 23 September 2013

Academic Editor: Stamatios Theocharis

Copyright (C) 2013 Zhen Liu et al. This is an open access article distributed under the Creative Commons Attribution License, which permits unrestricted use, distribution, and reproduction in any medium, provided the original work is properly cited.

\begin{abstract}
Objective. The purpose of the present study is to explore the correlation between nuclear expression of cyclin-dependent kinase inhibitor 1B (p27) and clinicopathologic features in nasopharyngeal carcinoma (NPC), including patient survival. Methods. Immunohistochemistry was used to examine the expression of p27 in 130 primary NPC tissues. The relationship between the levels of p27 expression and clinicopathologic characteristics was analyzed. Survival curves were plotted using the Kaplan-Meier method and compared using the log-rank test. The significance of various survival variables was analyzed using multivariate Cox proportional hazards model. Results. p27 was expressed in both nuclear and cytoplasmic compartments. Nuclear expression of p27 was inversely correlated with T classification and clinical stage. Patients with nuclear p27 expression had better overall survival rates than those without nuclear expression of p27. Further, we observed that nuclear expression of p27 was positively associated with survival time of NPC patients not only in N0-1 and M0 classifications but also in radiotherapy and chemotherapy treatment groups. Finally, we found that nuclear expression of p27 was not an independent prognostic factor for patients with NPC. Conclusions. Our findings hint that nuclear expression of p27 is a potentially favorable factor in the progression and prognosis of NPC.
\end{abstract}

\section{Introduction}

Nasopharyngeal carcinoma (NPC) is the most common primary malignant neoplasm of the nasopharynx with nearly $100 \%$ of cases associated with Epstein-Barr virus (EBV) infection [1]. It is rare in most populations but is frequent in both genders in areas such as Southeast Asia, Southern China, and North Africa. Due to its anatomical location and ambiguous symptoms, patients with this malignancy most often present with a cervical mass from metastatic spread to a lymph node or adjacent structures, thus leading to a poor prognosis.

Genetic susceptibility, environmental factors, EpsteinBarr virus infection, and epigenetic changes are key factors in nasopharynx carcinogenesis deregulating a number of significant genes and miRNAs, such as EZH2, HDGF, NESG1, CTGF, and miR-26a [2-8]. In a previous investigation, we used cDNA microarray to compare differentially expressed genes among NPC and noncancerous nasopharyngeal tissues. p27, a gene encoding cyclin-dependent kinase inhibitor $1 \mathrm{~B}$, was shown to be markedly decreased in NPC tissues, suggesting its potentially suppressive role in NPC pathogenesis [9].

p27 is an enzyme inhibitor encoded by the CDKN1B gene in humans that belongs to the Cip/Kip family of cyclindependent kinase (Cdk) proteins. The encoded protein binds to and prevents the activation of cyclin E-CDK2 or cyclin DCDK4 complexes, and thus controlling cell cycle progression 
at G1. Downregulation of P27 has been implicated in the progression of several malignancies, including lung cancer [10], hepatocellular carcinoma [11], salivary cancer [12], oral squamous cell carcinomas [13, 14], and gastric cancer [15]. Further, p27 was also observed to play a significant role in suppressing tumor pathogenesis $[16,17]$ yet its function in NPC has not been determined.

Our objective in this study is to investigate the expression of p27 in NPC tissues by immunohistochemistry and explore the correlation of p27 nuclear expression with clinicopathologic features and patient survival prognosis. Our results suggest that positive nuclear expression of p27 is a favorable factor for delaying disease progression and elevating overall survival time of NPC patients.

\section{Patients and Methods}

2.1. Sample Collection. One hundred and thirty (130) undifferentiated NPC paraffin-embedded specimens with clinical and prognosis information were obtained from patients ranging from 21 to 80 years old (median, 49.6 years) at the People's Hospital of Zhongshan City. These samples were totally absent of keratinization and lymphoepitheliomatous morphology with different degrees of infiltrating lymphocytic presence ranging from $5 \%$ to $55 \%$ in the carcinoma cells and stroma. Among these patients, there were 19 patients treated by radiotherapy alone, 4 by chemotherapy, and 97 by combination radiotherapy and chemotherapy. Eleven patients did not accept any treatment. For the use of these clinical materials for research purposes, prior consent from the patients and approval from the Ethics Committees of these two hospitals were obtained. All specimens had confirmed pathological diagnosis and were staged according to the 1997 NPC staging system of the UICC [18].

2.2. Immunohistochemistry. Immunohistochemistry was carried out according to our previous description [3, 4]. P27 antibody was used at a concentration of 1:100 (Santa Cruz Biotechnology, USA).

2.3. Evaluation of Staining. The immunohistochemically stained tissue sections were reviewed and scored separately by two pathologists blinded to the clinical parameters and evaluated for the presence of nuclear staining. Nuclear staining of $10 \%$ or more tumor cells was considered as positive for nuclear expression. On the contrary, less than $10 \%$ staining was regarded as negative nuclear expression.

2.4. Statistical Analyses. All statistical analyses were performed using SPSS 13.0. The $\chi^{2}$ test was used to analyze the relationship between the levels of p27 expression and clinicopathologic characteristics. Survival curves were plotted using the Kaplan-Meier method and compared using the log-rank test. The significance of various survival variables was analyzed using multivariate Cox proportional hazards model. A $P$ value of less than 0.05 was considered statistically significant.
TABLE 1: Correlation between the clinicopathologic characteristics and nuclear expression of $\mathrm{p} 27$ protein in NPC.

\begin{tabular}{|c|c|c|c|c|}
\hline \multirow{2}{*}{ Characteristics } & \multirow{2}{*}{$n$} & \multicolumn{2}{|c|}{ Nuclear expression of P27 (\%) } & \multirow{2}{*}{$P$} \\
\hline & & No & Yes & \\
\hline \multicolumn{5}{|l|}{ Gender } \\
\hline Male & 93 & 42 & 51 & \\
\hline Female & 37 & 22 & 15 & 0.175 \\
\hline \multicolumn{5}{|l|}{ Age (y) } \\
\hline$\geq 50$ & 68 & 34 & 34 & \\
\hline$<50$ & 62 & 30 & 32 & 0.863 \\
\hline \multicolumn{5}{|l|}{ Smoking } \\
\hline Yes & 32 & 12 & 20 & \\
\hline No & 98 & 52 & 46 & 0.156 \\
\hline \multicolumn{5}{|c|}{ Family tumor history } \\
\hline Yes & 4 & 2 & 2 & \\
\hline No & 126 & 62 & 64 & 1.000 \\
\hline \multicolumn{5}{|l|}{ T classification } \\
\hline $\mathrm{T}_{1}-\mathrm{T}_{2}$ & 90 & 36 & 54 & \\
\hline $\mathrm{T}_{3}-\mathrm{T}_{4}$ & 40 & 28 & 12 & 0.002 \\
\hline \multicolumn{5}{|l|}{$\mathrm{N}$ classification } \\
\hline $\mathrm{N}_{0}-\mathrm{N}_{1}$ & 73 & 32 & 41 & \\
\hline $\mathrm{N}_{2}-\mathrm{N}_{3}$ & 57 & 32 & 25 & 0.216 \\
\hline \multicolumn{5}{|c|}{ Distant metastasis } \\
\hline Yes & 10 & 5 & 5 & \\
\hline No & 120 & 59 & 61 & 1.000 \\
\hline \multicolumn{5}{|c|}{ TNM clinical stage } \\
\hline $\mathrm{I} \sim \mathrm{II}$ & 49 & 17 & 32 & \\
\hline III IV & 81 & 47 & 34 & 0.012 \\
\hline
\end{tabular}

\section{Results}

3.1. Immunohistochemical Analysis of p27 Protein Expression in NPC Tissues. We measured the expression levels and cellular localization of p27 protein in 130 archived paraffinembedded NPC samples using immunohistochemical staining (Figure 1). Specific p27 protein staining was detected in the nuclei and cytoplasm of malignant epithelial cells. Furthermore, we observed that 50.8\% (66/130) of cases showed clear expression of p27 (Table 1).

3.2. Relationship between Clinicopathological Characteristics and 27 Nuclear Expression in NPC Patients. The relationship between clinicopathological characteristics and p27 nuclear expression in individuals with NPC is summarized in Table 1. We did not find a significant association between p27 nuclear expression with patient's age, sex, smoking, N classification, or distant metastasis (M classification) in 130 NPC cases. However, we observed that p27 nuclear expression was inversely correlated with $\mathrm{T}$ classification $(P=0.002)\left(\mathrm{T}_{1}-\mathrm{T}_{2}\right.$ versus $\left.\mathrm{T}_{3}-\mathrm{T}_{4}\right)(P=0.012)$ and clinical stage (I-II versus IIIIV) $(P=0.012)$ in NPC patients (Table 1$)$. 


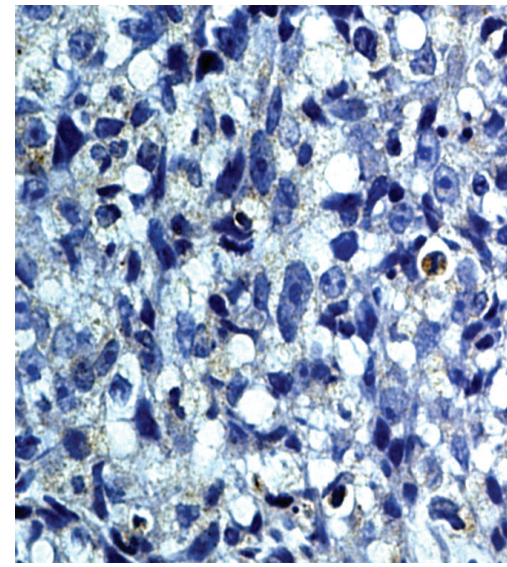

(a)

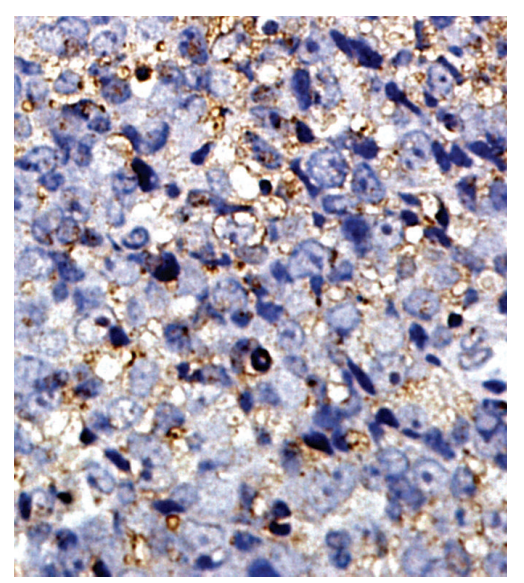

(b)

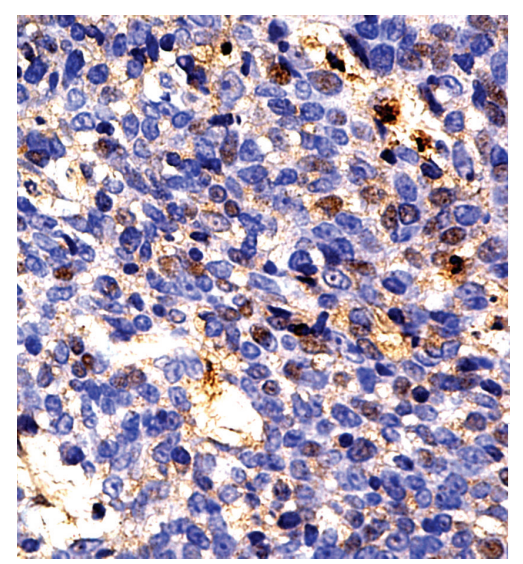

(c)

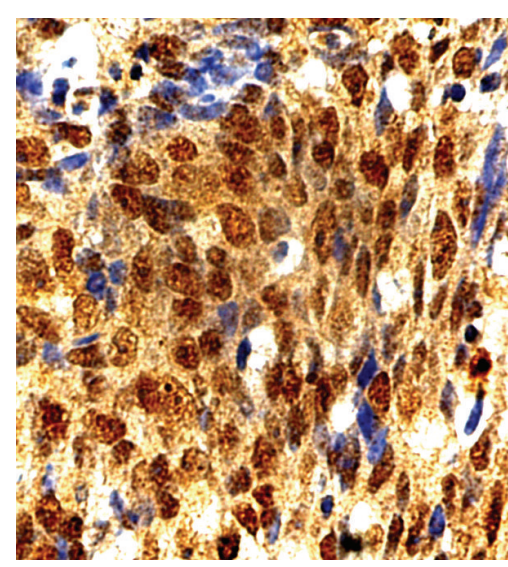

(d)

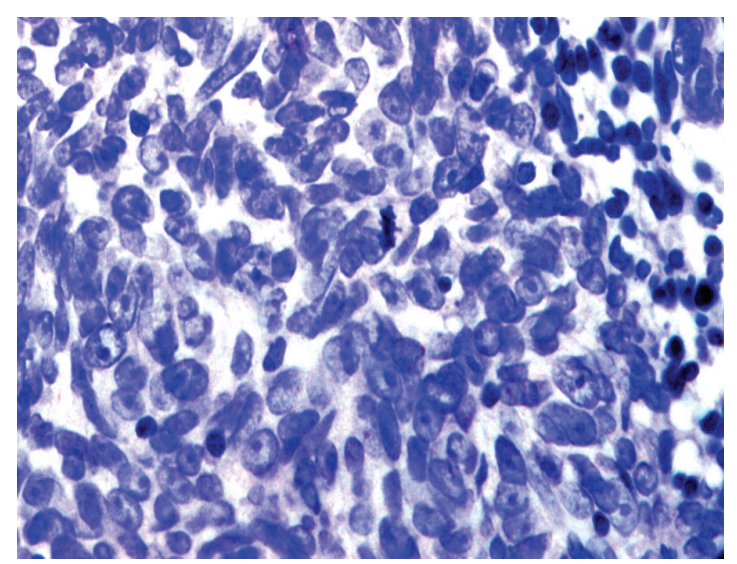

(e)

FIGURE 1: p27 protein is expressed in the cytoplasm and nuclei of malignant epithelial cells in NPC samples (original magnification: $\times 400$ ). (a) and (b) p27 protein expression in cytoplasm of NPC tissues (negative nuclear expression); (c)-(d) p27 protein expression in the nucleus of NPC tissues (positive nuclear expression). (e) Negative control.

3.3. p27 Nuclear Expression Is Associated with Overall Survival Time of NPC. To investigate the prognostic value of p27 protein expression in NPC, we assessed the association between the levels of p27 nuclear expression and patients' survival using Kaplan-Meier analysis with the log-rank test. In 130 NPC cases with prognosis information, we observed that nuclear expression of p27 was significantly correlated with the overall survival of NPC patients. Patients with nuclear expression had better prognoses than those with negative nuclear expression of p27 (Figure 2) $(P=$ 0.007).

3.4. 27 Nuclear Expression Is Correlated with Survival Time of NPC Patients with $N_{0}-N_{1}$ Classification and $M_{0}$ Classification. We further analyzed the correlation of p27 nuclear expression with prognosis for NPC patients by stratification analysis against $\mathrm{T}$ classification, $\mathrm{N}$ classification, $\mathrm{M}_{0}$ classification, and clinical stage. Positive p27 protein nuclear expression was significantly associated with survival time for NPC patients in $\mathrm{N}_{0}-\mathrm{N}_{1}$ classification and $\mathrm{M}_{0}$ classification but did not correlate with $\mathrm{T}_{1}-\mathrm{T}_{2}, \mathrm{~T}_{3}-\mathrm{T}_{4}$, or $\mathrm{N}_{2}-\mathrm{N}_{3}$ classifications nor clinical stages I-II or III-IV. Patients with nuclear expression had better prognosis than those with negative nuclear expression of $\mathrm{p} 27$ in $\mathrm{N}_{0}-\mathrm{N}_{1}$ classification $(P=0.002)$ and $\mathrm{M}_{0}$ classification $(P=0.003)$ (Figure 3$)$.

3.5. p27 Nuclear Expression Is Favorable for Prognosis of NPC Patients with Radiotherapy and Chemotherapy. We also explored the association of $\mathrm{p} 27$ nuclear expression with NPC patient survival in groups treated by chemotherapy and radiotherapy. We found a significant correlation between p27 nuclear expression and NPC prognosis in the chemotherapy and radiotherapy treated groups, but not in untreated patients. Patients with nuclear expression had better prognosis than those with negative nuclear expression of p27 after the respective treatment of chemotherapy $(P=0.009)$ and radiotherapy $(P=0.023)$ (Figure 4$)$.

3.6. Nuclear Expression of 27 Is Not an Independent Prognosis Factor for NPC Patients. Univariate analyses showed that radiotherapy, $\mathrm{T}, \mathrm{N}$, and $\mathrm{M}$ classifications, clinical stages, and p27 nuclear expression were all significantly correlated with 
TABLE 2: Summary of univariate and multivariate Cox regression analysis of overall survival duration.

\begin{tabular}{|c|c|c|c|c|c|c|}
\hline \multirow{2}{*}{ Parameter } & \multicolumn{3}{|c|}{ Univariate analysis } & \multicolumn{3}{|c|}{ Multivariate analysis } \\
\hline & $P$ & $\mathrm{HR}$ & $95 \% \mathrm{CI}$ & $P$ & HR & $95 \% \mathrm{CI}$ \\
\hline \multicolumn{7}{|l|}{ Gender } \\
\hline Male versus female & 0.485 & 0.488 & $0.665-2.361$ & & & \\
\hline \multicolumn{7}{|l|}{ Age } \\
\hline$\geq 50$ versus $<50$ years & 0.787 & 0.073 & $0.620-1.881$ & & & \\
\hline \multicolumn{7}{|l|}{ Family tumor history } \\
\hline Yes versus no & 0.349 & 0.877 & $0.000-28.401$ & & & \\
\hline \multicolumn{7}{|l|}{ Smoking } \\
\hline Yes versus no & 0.387 & 0748 & $0.368-1.474$ & & & \\
\hline \multicolumn{7}{|l|}{ Chemotherapy } \\
\hline Yes versus no & 0.700 & 1.153 & $0.560-2.372$ & & & \\
\hline \multicolumn{7}{|l|}{ Radiotherapy } \\
\hline Yes versus no & 0.005 & 0.369 & $0.184-0.742$ & 0.990 & 0.994 & $0.419-2.358$ \\
\hline \multicolumn{7}{|l|}{ T classification } \\
\hline$T_{1}-T_{2}$ versus $T_{3}-T_{4}$ & 0.000 & 28.042 & $2.674-8.496$ & 0.014 & 2.725 & $1.222-6.075$ \\
\hline \multicolumn{7}{|l|}{$\mathrm{N}$ classification } \\
\hline $\mathrm{N}_{0}-\mathrm{N}_{1}$ versus $\mathrm{N}_{2}-\mathrm{N}_{3}$ & 0.000 & 2.950 & $1.662-5.237$ & 0.240 & 1.633 & $0.720-3.702$ \\
\hline \multicolumn{7}{|l|}{ M classification } \\
\hline $\mathrm{M}_{0}$ versus $\mathrm{M}_{1}$ & 0.000 & 35.042 & $5.031-24.906$ & 0.005 & 4.461 & $1576-12.633$ \\
\hline \multicolumn{7}{|l|}{ TNM clinical stage } \\
\hline I-II versus III-IV & 0.000 & 19.386 & $3.592-27.943$ & 0.051 & 3.758 & $0.992-14.239$ \\
\hline \multicolumn{7}{|l|}{ p27 nuclear expression } \\
\hline Positive expression versus negative expression & 0.009 & 0.460 & $0.257-0.822$ & 0.690 & 0.878 & $0.464-1.661$ \\
\hline
\end{tabular}

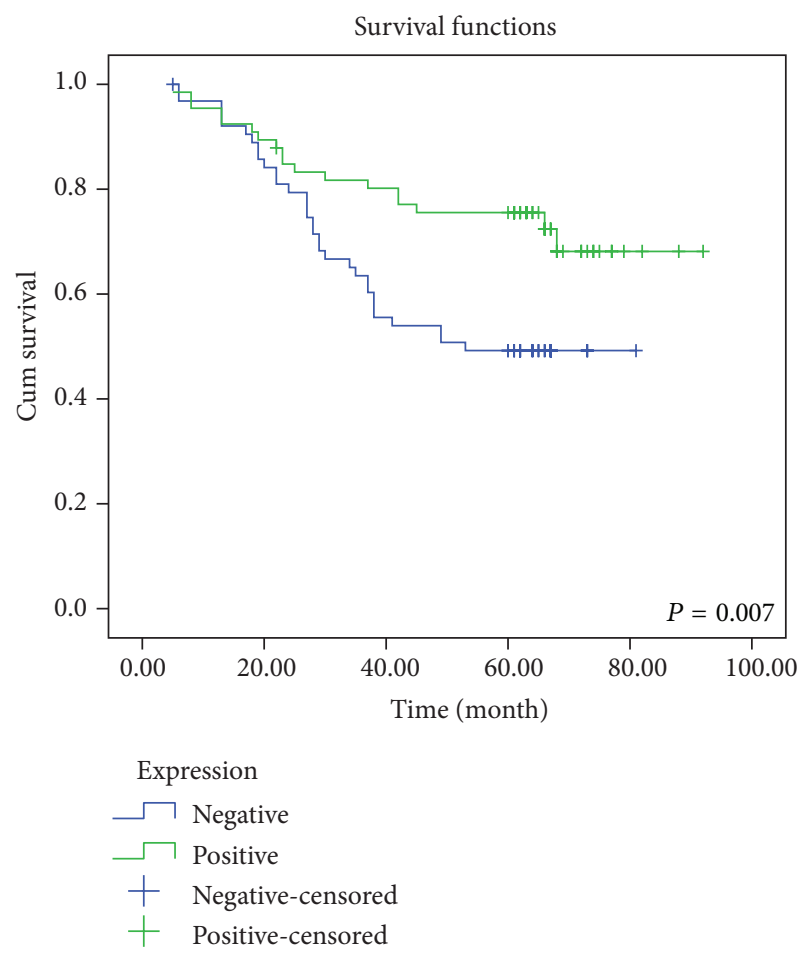

Figure 2: Nuclear expression or nuclear expression level of p27 protein predicts NPC patients' overall survival time. Patients with nuclear positive expression of p27 had better survival than those with negative nuclear expression of $\mathrm{p} 27$. patients' survival $(P=0.005, P<0.001, P<0.001$, $P<0.001, P<0.001$, and $P=0.009$, resp.). To determine whether p27 is an independent prognostic factor for NPC, we performed multivariate analysis of p 27 protein expression levels adjusted for radiotherapy, $\mathrm{T}$ classification, $\mathrm{N}$ classification, M classification, and clinical stages of NPC patients. These results showed that the level of p27 expression was not an independent prognostic factor for NPC $(P=0.690)$ (Table 2).

\section{Discussion}

P27 is a key cell cycle protein kinase inhibitor which forms a nuclear complex with CCND1 and CDK4. This prevents CDK4 from adding phosphate residues to its principal substrate, retinoblastoma ( $\mathrm{pRb}$ ) protein blocking cell cycle G1/S transition. P27 expression levels are inversely related with CCND1 and CDK4 in NPC [9, 19]. Furthermore, p27 is able to bind other Cdk proteins when complexed to cyclin subunits such as cyclin E/Cdk2 and cyclin A/Cdk2 and suppress cell cycle transition. Decreased expression of p27 has been described in many tumors, including bladder cancer [20], melanoma [21], and ovarian cancer [22], and is associated with unfavorable clinical parameters and poor outcomes in these tumor types. Del Pizzo et al. found decreased expression of $\mathrm{p} 27 \mathrm{Kip} 1$ in poorly differentiated bladder tumors (grades III) compared to well and moderately differentiated (grades I and II) tumors and it was an unfavorable prognostic 
Survival functions
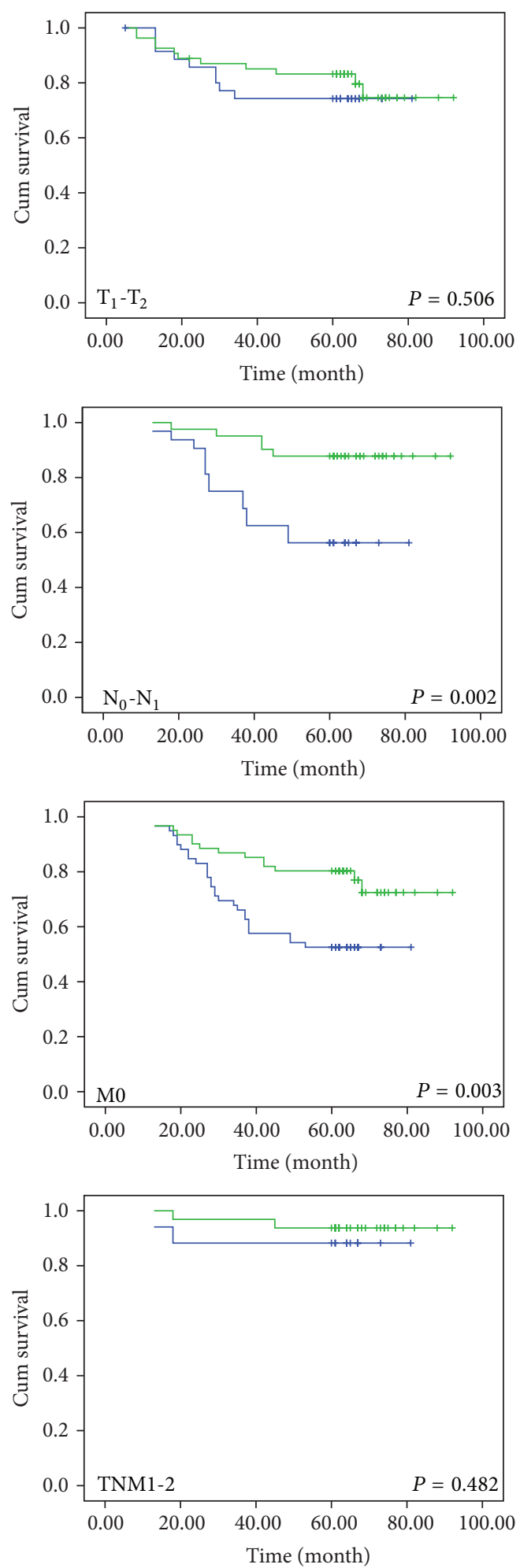

Expression

$\neg$ Negative

$\neg$ Positive

+ Negative-censored

+ Positive-censored
Survival functions
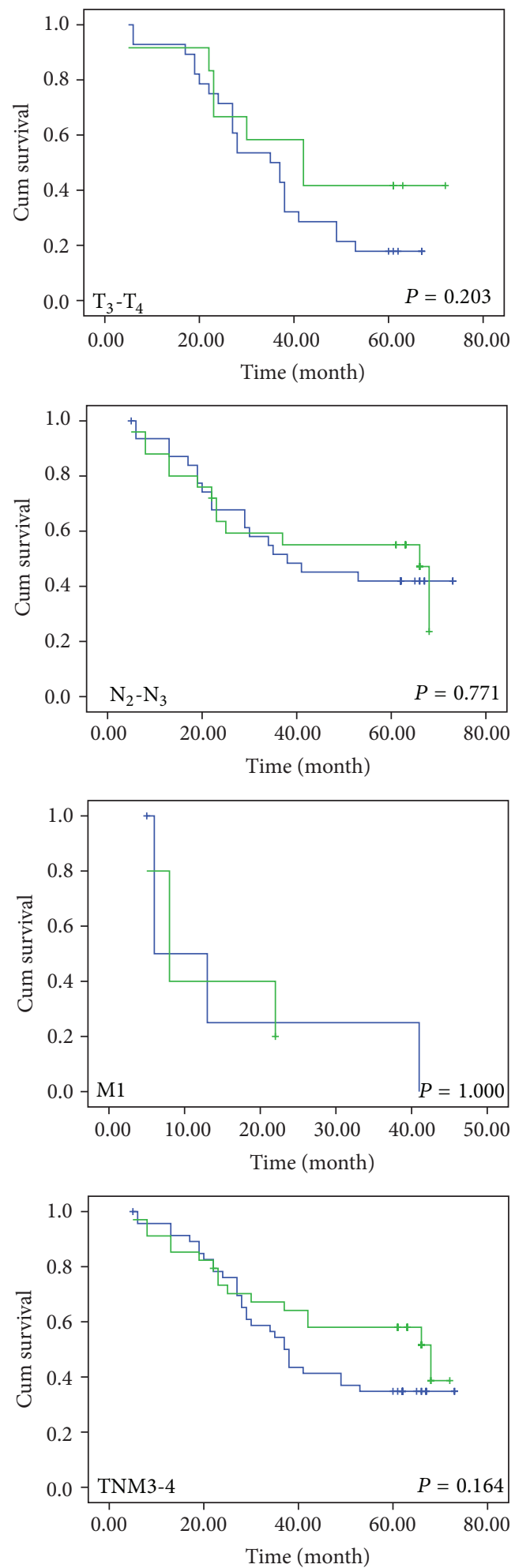

Expression

$\neg$ Negative

$\neg$ Positive

+ Negative-censored

+ Positive-censored

FIGURE 3: The correlation of p27 expression with NPC patients' survival time in strata analysis in TNM stage, T classification, N classification, and M classification P27 protein expression was significantly associated with the survival time for NPC patients with $\mathrm{N}_{0}-\mathrm{N}_{1}$ or $\mathrm{M}_{0}$ classifications. NPC patients with nuclear expression of p27 protein had longer survival times. 

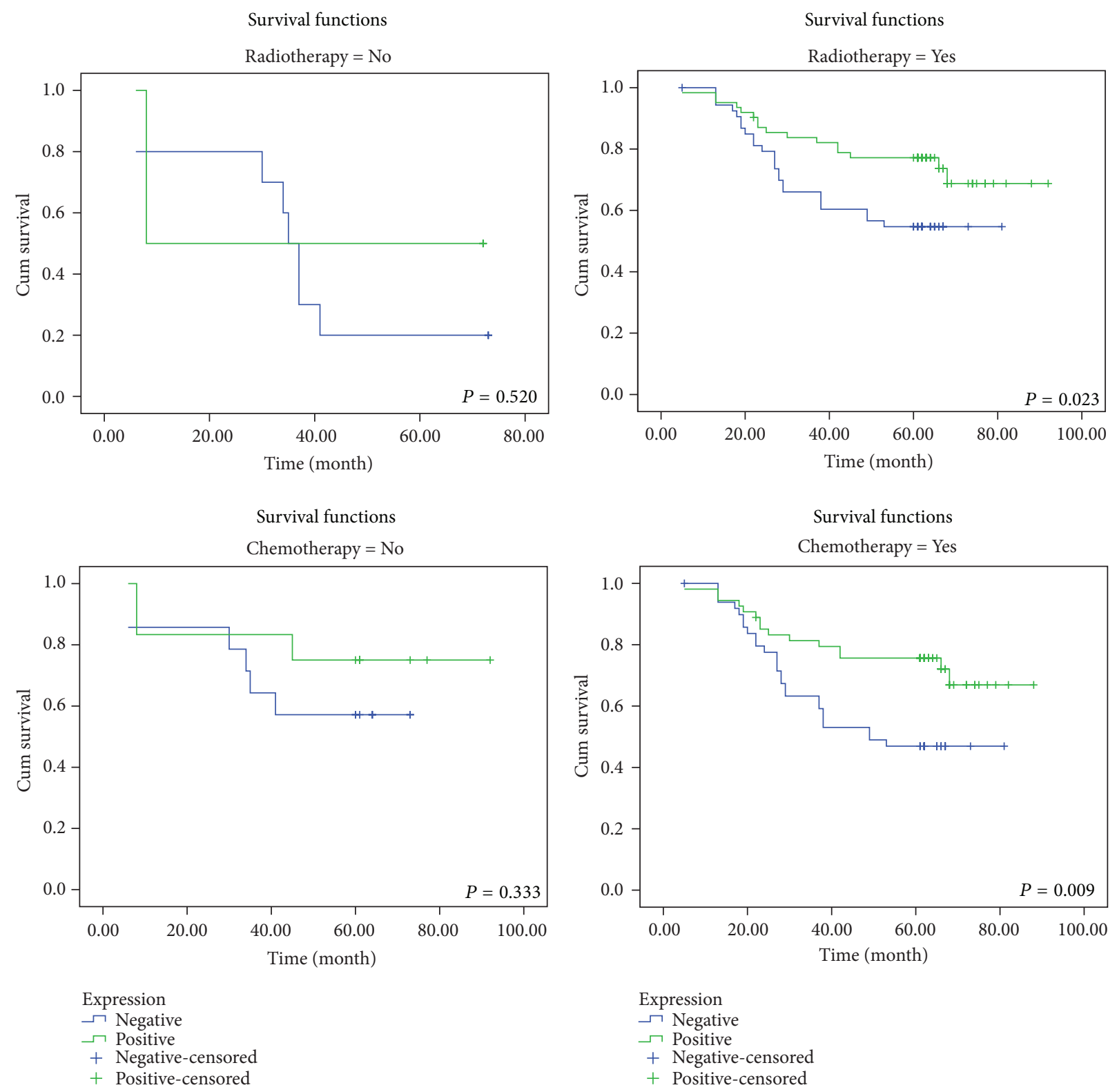

(a)

(b)

FIGURE 4: p27 nuclear expression was favorable for radiotherapy and chemotherapy treated NPC patients. p27 protein expression was significantly associated with the survival time for NPC patients treated by radiotherapy and chemotherapy but not for those untreated patients. (a) Patients with nuclear expression had better prognoses than those with negative nuclear expression of p27 after radiotherapy. (b) Patients with nuclear expression had better prognosis than those with negative nuclear expression of p27 after chemotherapy.

factor. Flørenes et al. observed a virtual complete loss of p27Kip1 protein expression in nodular melanoma which was a prognostic indicator of early relapse. In ovarian cancer, increased expression of p27 was associated with long-term survival of patients. These results strongly support that p27 functions as a tumor suppressor during carcinogenesis.

In previous investigation, Fan et al. reported that p27 expression was downregulated in EBV-infected nasopharyngeal carcinoma [23], a result similar to our findings in NPC [8]. Furthermore, suppression of p27 was also observed by LMP1 [24], a key EBV-expressing oncoprotein promoting the transformation of human nasopharyngeal epithelial cells [25]. These suggested that p27 is a significant gene downregulated during NPC progression, yet its correlation with clinical features and the prognostic value of NPC is not clear.

In this study, we evaluated the expression of p27 in NPC by immunohistochemistry and found that p27 protein was coexpressed in cytoplasm and nucleus of NPC tissues. This finding was consistent with previous reports from other tumors [10, 11, 15, 20-22]. Furthermore, we also observed that over half of NPC cases showed positive nuclear expression of p27. Because p27 drives cell cycle progression 
when it translocates into the nucleus [26], we analyzed the correlation of p27 nuclear expression with clinical features of NPC patients and observed that p27 nuclear expression was inversely correlated with $\mathrm{T}$ classification and clinical stage. Furthermore, we found that nuclear expression of p27 protein in NPC was positively correlated with patient's overall survival time. Patients with nuclear expression of p27 protein had an overall longer survival time. Our results are similar to Del Pizzo, Flørenes, and Newcomb et al's reports from other tumors and together suggest that p27 nuclear expression inhibits the pathogenesis of NPC [20-22].

Further, survival prognosis was assessed by stratification analysis against $\mathrm{T}$ classification, $\mathrm{N}$ classification, $\mathrm{M}$ classification, and clinical stage. We observed that p27 nuclear expression was inversely associated with the survival time only for NPC patients with $\mathrm{N}_{0}-\mathrm{N}_{1}$ or $\mathrm{M}_{0}$ classifications. Patients with nuclear expression had better prognosis than those of negative nuclear expression. These results hinted that p27 nuclear expression is a good biomarker for evaluating the prognosis of NPC patients with $\mathrm{N}_{0}-\mathrm{N}_{1}$ and $\mathrm{M}_{0}$ classifications.

P27 functions as a cell cycle inhibitor blocking cell growth in many tumor types $[27,28]$. We suspected that nuclear expression of p27 might be associated with the sensitivity to radiotherapy or chemotherapy, which would increase the overall survival time of NPC patients. Consistent with our hypothesis, we observed that patients with nuclear expression of $\mathrm{p} 27$ protein had an overall longer survival time in radiotherapy and chemotherapy groups, but no correlation in nontreated groups. This finding suggested that nuclear expression of p27 protein might decrease the resistance of radiotherapy and chemotherapy for NPC patients.

Finally, we evaluated the possibility of p27 nuclear expression as an independent prognostic factor for NPC. According to univariate analysis, patient's overall survival is inversely proportional to T/N/M classification and clinical stage but positively correlated with p27 nuclear expression and radiotherapy treatment. Multivariate analyses showed that nuclear expression of p27 protein was not an independent predictor of prognosis for NPC patients regardless of patient disease status.

In summary, our results provide evidence that lower nuclear expression of p27 may be involved in the clinical progression and poor prognosis of NPC patients. However, it could not serve as a potential independent prognostic factor for NPC.

\section{Conflict of Interests}

The authors declare that they have no conflict of interests.

\section{Authors' Contribution}

Zhen Liu, Yufei Long, Yajie Zhang, and Wei Huang contributed equally to this work.

\section{Acknowledgments}

This study was supported by National Nature Science Fund of China (no. 81071632), New Star Plan of Pearl River Science and Technology from Guangzhou City (no. 2011J2200009), and Yangchengz Scholar Research Projects from Universities of Guangzhou (no. 12A011D).

\section{References}

[1] D. K. Paramita, J. Fachiroh, S. M. Haryana, and J. M. Middeldorp, “Two-step epstein-barr virus immunoglobulin A enzyme-linked immunosorbent assay system for serological screening and confirmation of nasopharyngeal carcinoma," Clinical and Vaccine Immunology, vol. 16, no. 5, pp. 706-711, 2009.

[2] S. K. Kassim, S. A. Ibrahim, S. Eissa et al., "Epstein-barr virus, human papillomavirus, and flow cytometric cell cycle kinetics in nasopharyngeal carcinoma and inverted papilloma among Egyptian patients," Disease Markers, vol. 14, no. 2, pp. 113-120, 1998.

[3] N. M. Alajez, W. Shi, A. B. Y. Hui et al., "Enhancer of Zeste homolog 2 (EZH2) is overexpressed in recurrent nasopharyngeal carcinoma and is regulated by miR-26a, miR-101, and miR98," Cell Death and Disease, vol. 1, no. 10, Article ID e85, 2010.

[4] S. Wang and W. Fang, "Increased expression of hepatomaderived growth factor correlates with poor prognosis in human nasopharyngeal carcinoma," Histopathology, vol. 58, no. 2, pp. 217-224, 2011.

[5] Z. Liu, W. Luo, Y. Zhou et al., "Potential tumor suppressor NESG1 as an unfavorable prognosis factor in nasopharyngeal carcinoma," PLoS ONE, vol. 6, no. 11, Article ID e27887, 2011.

[6] W. R. Luo, A. B. Wu, W. Y. Fang, S. Y. Li, and K. T. Yao, "Nuclear expression of $\mathrm{N}$-cadherin correlates with poor prognosis of nasopharyngeal carcinoma," Histopathology, 2012.

[7] X. Zeng, J. Xiang, M. Wu et al., "Circulating miR-17, miR-20a, miR-29c, and miR-223 combined as non-invasive biomarkers in nasopharyngeal carcinoma," PLoS One, vol. 7, no. 10, Article ID e46367, 2012.

[8] X. Yu, Y. Zhen, H. Yang et al., "Loss of connective tissue growth factor as an unfavorable prognosis factor activates miR-18b by PI3K/AKT/C-Jun and C-Myc and promotes cell growth in nasopharyngeal carcinoma," Cell Death \& Disease, vol. 16, no. 4, Article ID e634, 2013.

[9] W. Fang, X. Li, Q. Jiang et al., "Transcriptional patterns, biomarkers and pathways characterizing nasopharyngeal carcinoma of southern China," Journal of Translational Medicine, vol. 6 , no. 32, 2008.

[10] A. Osoegawa, I. Yoshino, S. Tanaka et al., "Regulation of p27 by S-phase kinase-associated protein 2 is associated with aggressiveness in non-small-cell lung cancer," Journal of Clinical Oncology, vol. 22, no. 20, pp. 4165-4173, 2004.

[11] K. J. Nan, Z. Jing, and L. Gong, "Expression and altered subcellular localization of the cyclin-dependent kinase inhibitor p27Kip1 in hepatocellular carcinoma," World Journal of Gastroenterology, vol. 10, no. 10, pp. 1425-1430, 2004.

[12] O. Ben-Izhak, S. Akrish, S. Gan, and R. M. Nagler, "p27 and salivary cancer," Cancer Immunology, Immunotherapy, vol. 58, no. 3, pp. 469-473, 2009.

[13] T. Fillies, M. Woltering, B. Brandt et al., "Cell cycle regulating proteins p21 and p27 in prognosis of oral squamous cell carcinomas," Oncology reports, vol. 17, no. 2, pp. 355-359, 2007.

[14] K. Harada, S. Supriatno, H. Yoshida, and M. Sato, "Low p27Kip1 expression is associated with poor prognosis in oral squamous cell carcinoma," Anticancer Research, vol. 22, no. 5, pp. 29852989, 2002. 
[15] G. Galizia, F. Ferraraccio, E. Lieto et al., "p27 downregulation and metallothionein overexpression in gastric cancer patients are associated with a poor survival rate," Journal of Surgical Oncology, vol. 93, no. 3, pp. 241-252, 2006.

[16] P. K. Singha, S. Pandeswara, M. A. Venkatachalam, and P. Saikumar, "Manumycin A inhibits triple-negative breast cancer growth through LC3-mediated cytoplasmic vacuolation death," Cell Death \& Disease, vol. 4, no. 1, Article ID e457, 2013.

[17] R. Nassirpour, P. P. Mehta, S. M. Baxi, and M. J. Yin, "miR-221 promotes tumorigenesis in human triple negative breast cancer cells," PLoS One, vol. 8, no. 4, Article ID e62170, 2013.

[18] A. Tatsumi-Tamori, T. Miwa, T. Yoshizaki, and M. Furukawa, "Clinical evaluation of staging system for nasopharyngeal carcinoma: comparison of fourth and fifth editions of UICC TNM classification," Annals of Otology, Rhinology and Laryngology, vol. 109, no. 12, pp. 1125-1129, 2000.

[19] W. Zhang, Z. Zeng, Y. Zhou et al., "Identification of aberrant cell cycle regulation in Epstein-Barr virus-associated nasopharyngeal carcinoma by cDNA microarray and gene set enrichment analysis," Acta Biochimica et Biophysica Sinica, vol. 41, no. 5, pp. 414-428, 2009.

[20] J. J. Del Pizzo, A. Borkowski, S. C. Jacobs, and N. Kyprianou, "Loss of cell cycle regulators p27(Kip1) and cyclin E in transitional cell carcinoma of the bladder correlates with tumor grade and patient survival," American Journal of Pathology, vol. 155, no. 4, pp. 1129-1136, 1999.

[21] V. A. Flørenes, G. M. Mælandsmo, R. S. Kerbel, J. M. Slingerland, J. M. Nesland, and R. Holm, "Protein expression of the cell-cycle inhibitor p27(Kip1) in malignant melanoma: inverse correlation with disease-free survival," American Journal of Pathology, vol. 153, no. 1, pp. 305-312, 1998.

[22] E. W. Newcomb, M. Sosnow, R. I. Demopoulos, A. ZeleniuchJacquotte, J. Sorich, and J. L. Speyer, "Expression of the cell cycle inhibitor p27(KIP1) is a new prognostic marker associated with survival in epithelial ovarian tumors," American Journal of Pathology, vol. 154, no. 1, pp. 119-125, 1999.

[23] S. Q. Fan, J. Ma, J. Zhou et al., "Differential expression of Epstein-Barr virus-encoded RNA and several tumor-related genes in various types of nasopharyngeal epithelial lesions and nasopharyngeal carcinoma using tissue microarray analysis," Human Pathology, vol. 37, no. 5, pp. 593-605, 2006.

[24] Y. P. Mei, J. M. Zhou, Y. Wang et al., "Silencing of LMP1 induces cell cycle arrest and enhances chemosensitivity through inhibition of AKT signaling pathway in EBV-positive nasopharyngeal carcinoma cells," Cell Cycle, vol. 6, no. 11, pp. 1379-1385, 2007.

[25] A. K. Lo, K. W. Lo, C. W. Ko, L. S. Young, and C. W. Dawson, "Inhibition of the LKB1-AMPK pathway by the Epstein-Barr virus-encoded LMP1 promotes proliferation and transformation of human nasopharyngeal epithelial cells," The Journal of Pathology, vol. 230, no. 3, pp. 336-346, 2013.

[26] P. J. Hodul, Y. Dong, K. Husain et al., "Vitamin E $\delta$-tocotrienol induces $\mathrm{p} 27^{\text {Kip } 1}$-dependent cell-cycle arrest in pancreatic cancer cells via an E2F-1-dependent mechanism," PLoS One, vol. 8, no. 2, Article ID e52526, 2013.

[27] S. Ståhl, V. O. Kaminskyy, G. Efazat et al., "Inhibition of Ephrin B3-mediated survival signaling contributes to increased cell death response of non-small cell lung carcinoma cells after combined treatment with ionizing radiation and PKC 412," Cell Death \& Disease, vol. 10, no. 4, Article ID e454, 2013.

[28] J. Bai, P. Mei, C. Zhang et al., "BRG1 is a prognostic marker and potential therapeutic target in human breast cancer," PLoS One, vol. 8, no. 3, Article ID e59772, 2013. 


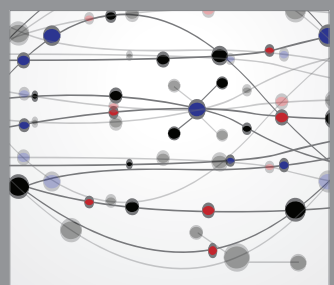

The Scientific World Journal
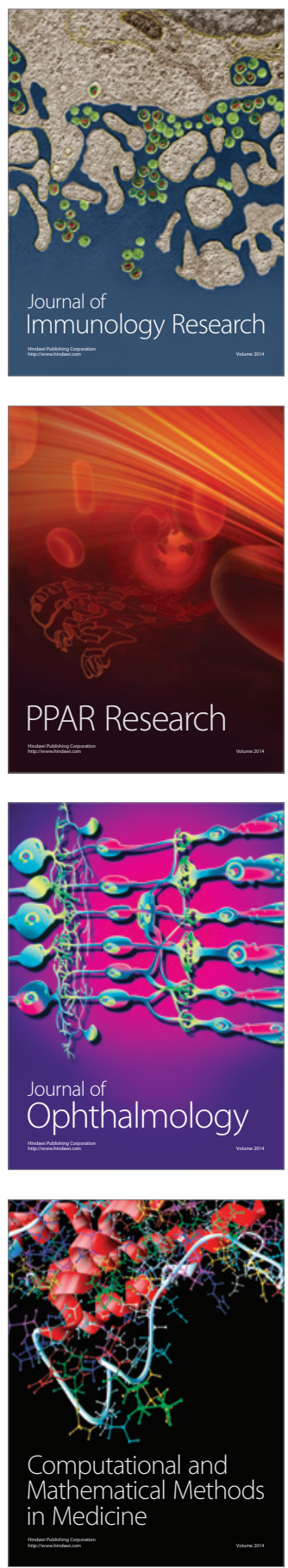

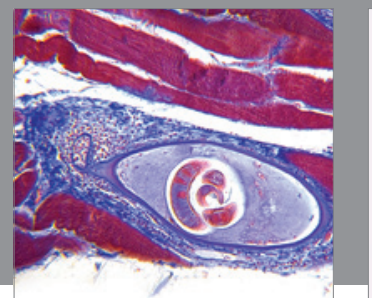

Gastroenterology

Research and Practice
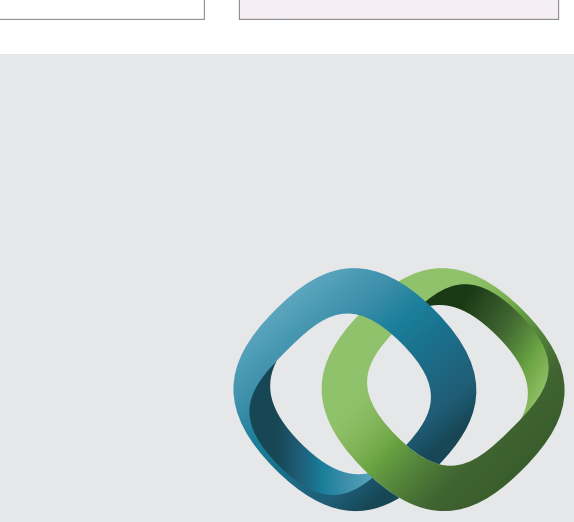

\section{Hindawi}

Submit your manuscripts at

http://www.hindawi.com
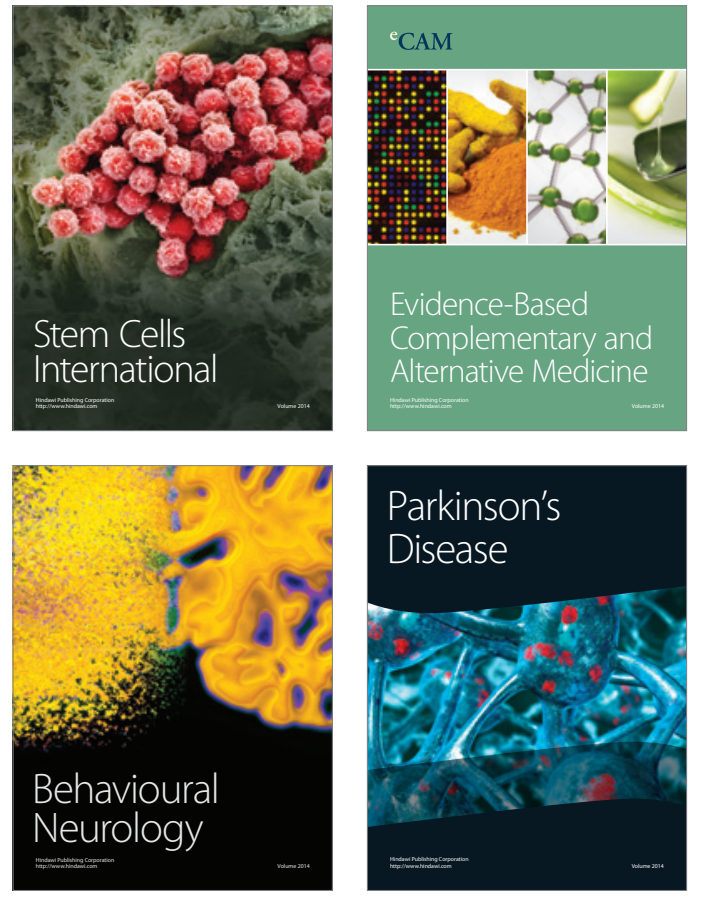
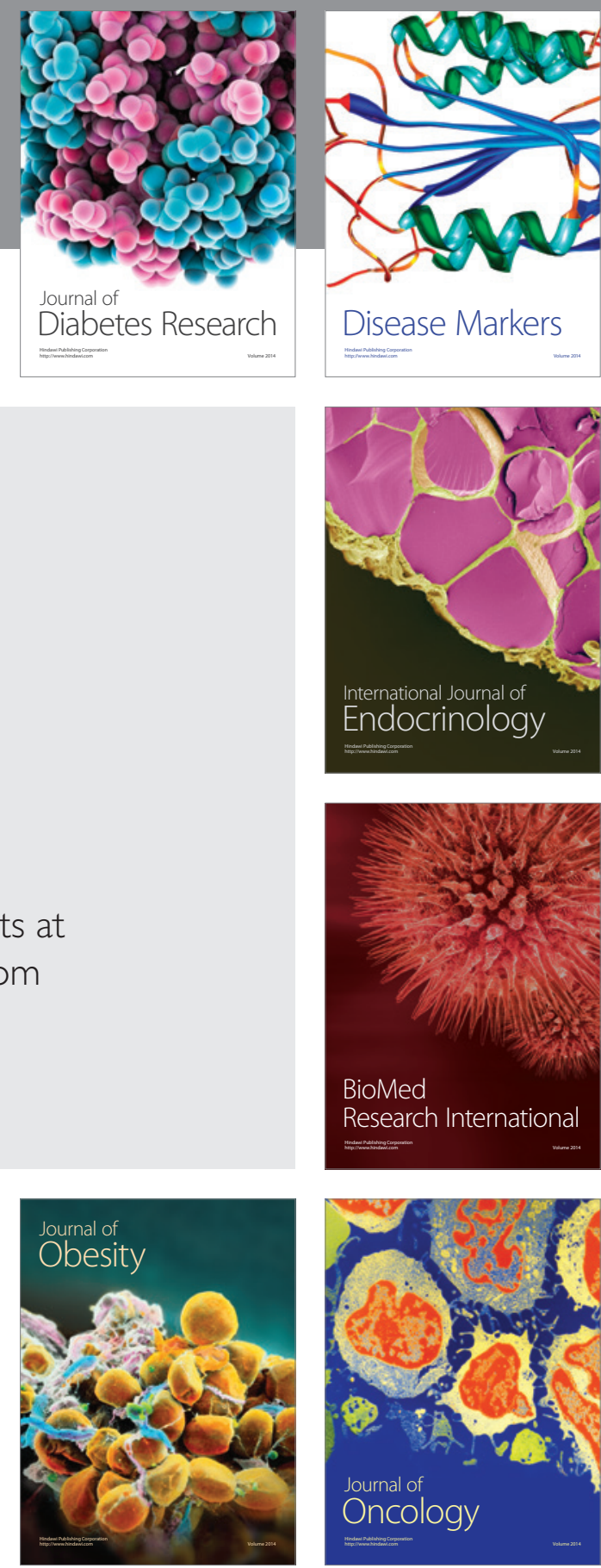

Disease Markers
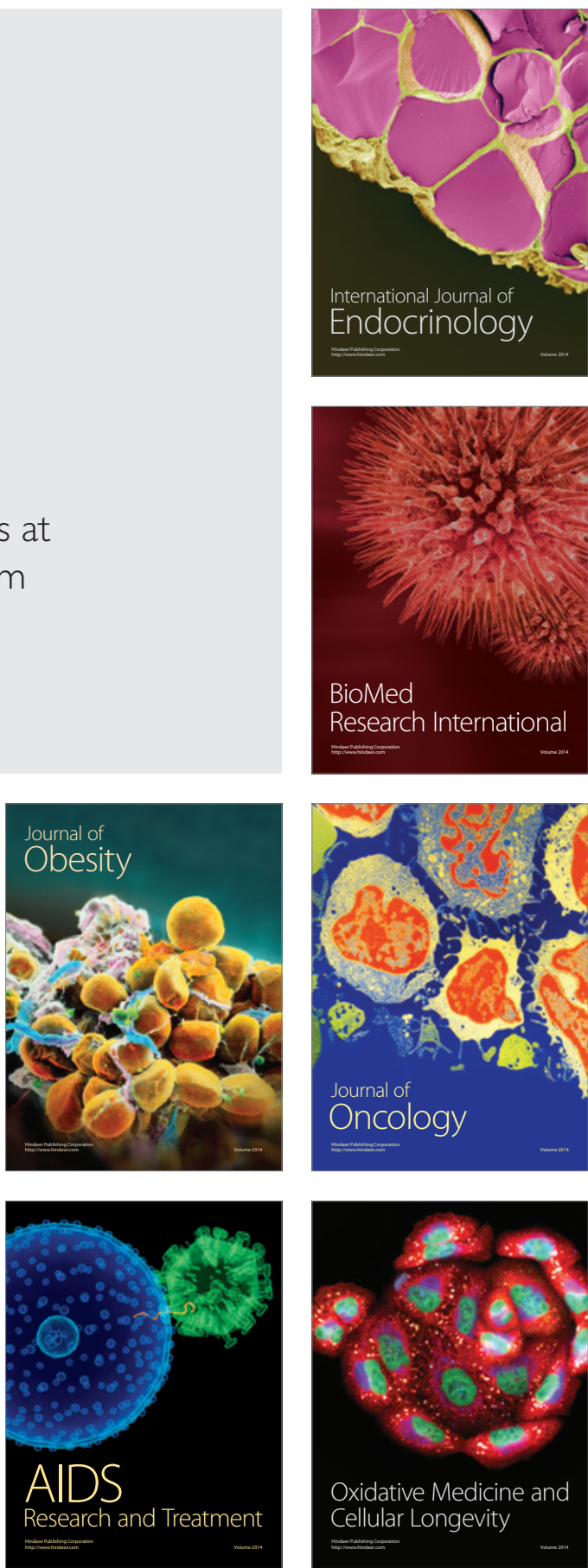